\title{
EFL Reading Comprehension Classes with Cultural Consciousness-raising Orientation and Multicultural Personal Traits Development
}

\author{
Hossein Samadi Bahrami \\ Department of International Languages, School of International Relation (SIR), Tehran, Iran
}

\begin{abstract}
Investment and personality development in SL learning is gaining momentum (Norton, 2000, Norton and Toohey, 2002; Kramsch, 2005; Norton, 2010). Therefore, pedagogical aspects of identity require to be investigated to facilitate learning process. This study investigated the impact of Reading Comprehension classes with consciousness-raising orientation on Multicultural Personality Traits' development in EFL students compared with EFL students undergoing regular reading comprehension classes with no specific treatments. Eighty three EFL students in five RC classes were randomly selected. Two classes were treated as the experimental group and three classes as control group. Multicultural Personality Traits Questioner, a personality assessment questionnaire developed by Van Der Zee and Oudenhoven (2000) was used to measure their five personality features, recognized as Multicultural Personality Traits - Cultural Empathy, Openmindedness, Social Initiative, Emotional Stability, and Flexibility. The analyses of the collected revealed that there was not a statistically significant increase in total Multicultural Personality Traits from $t_{1}(M=268.03$, $\mathrm{SD}=12.636)$ to $\mathrm{t}_{2}[\mathrm{M}=271.14, \mathrm{SD}=11.565, \mathrm{t}(34)=1.588, \mathrm{p} \leq .05]$. But there was a statistically significant value found in the scores of Cultural Empathy $(C E)$ from $t_{1}(M=55.20, S D=2.67)$ to $t_{2}[M=56.49, S D=2.79, t(34)$ $=2.35 ; p \leq .05]$.
\end{abstract}

Index Terms-EFL reading comprehension, cultural consciousness-raising orientation, multicultural personality traits development

\section{INTRODUCTION}

Language and culture are intermingled in each other and mutually serve each other. Furthermore, their collective entity constructs identity in individuals and communities alike (Peterson \& Coltrane, 2003). Cultural entities are so essential to language that extraction of culture from language would lead any languages to the verge of extinction and that is why almost all language learning programs and materials either intentionally or inevitably include cultural aspects of language alongside its linguistic features. Therefore, both L1 language acquisition and L2 language learning are accompanied with cultural acquisition (Fogle 2007; Hinkel, 2006; Eglin, 2000). Hence, there exists the potential possibility that enhancing L2-associted cultural traits in L2 learners might help pave the way for their L2 proficiency achievements.

There are very strong reasons for the inclusion of culture and cultural understanding in the curriculum of the second or foreign language programs. The very first one is that language is almost nonexistent if it is void of its cultural features. A culture-free language would be just a frame with no contents and ingredients, for culture is the substance and language is the frame to provide it a manifestable shape and the possibility of exchange. The second reason for the inclusion of culture in the syllabi is that learning a second language without cultural understanding would result in an imperfect knowledge of the second language in which language learners might possess entire linguistic features of the new language, but still have problems in expressing themselves properly and making the right interpretations of the received materials. A second language speaker with almost perfect linguistic competence but little cultural understanding would sound strange, have problems in establishing meaningful communication with native speakers of the second language and authentic texts, and would construe too many misunderstandings. Therefore, the intercultural competence is what a perfect FL speaker needs next to linguistic, communicative and pragmatic competences. This reading of culture and language unanimity has constructed the theoretical foundation of this study to investigate the impact of Cultural Awareness Raising Approach in teaching Reading Comprehension classes on the EFL students by Pre and post testing their Multicultural Personality Traits developments.

\section{a. Background}

The amount of time and capital invested on L2 learning by individuals themselves, their families, institutions and states is really tremendous. Iranian TEFL community has not dealt with culture-related issues in EFL teaching and learning in the curriculums, teaching materials, and teaching strategies properly yet. As mentioned earlier, cultural ingredients of every language cannot be removed from every aspect of language teaching programs because of their ubiquitous nature in language. But this cultural aspect of EFL has not received the pedagogical, sociocultural and psychological attention and care it deserves. 
There is no doubt that successful L2 learning in its totality will necessarily be accompanied by Second Culture Acquisition (SCA) (Hamers \& Blance, 2000). L2 learning is, to an acceptable level, categorized into second language acquisition (SLA) and foreign language learning (FLL), but L2 culture is altogether an acquisitional phenomenon both in SLA and FLL. Of course its intensity in SLA can reasonably be accepted to be greater than FLL but its quality is of the same kind and nature. The only difference is that the degree or amount of L2 culture acquisition in the SL context will be much greater than the FL context. Furthermore, a FL learner, living in his native language socio-cultural context, would expectedly undergo greater challenges and resistance, either consciously or unconsciously, in evaluating, gaining, and exercising his new language culture. Hence, L2 culture acquisition in any L2 learning, whether FL or SL, is an inevitable task and its various sociocultural as well as pedagogical aspects call for proper and profound understandings and management.

\section{b. Review of the related literature}

Culture, owing to its sensitive and between-the-line nature, has yielded itself very little to academic studies compared to other aspects of EFL. Of course within ESL there have been studies conducted in countries native to English language and there are also studies in the EFL area on Japanese students (Yasuko, 2003), Koreans (Ahn, 2007), and Chinese (Feng, 2009). But when cultural studies in the EFL field in the Middle East countries are searched, specifically in Iran, the shortcoming in this area compared to the other linguistic aspects of EFL is easily recognized.

L2 learning and teaching is getting richer and richer day by day by integrating greater number of variables together and defining every one of these variable's sphere of influence on L2 learning and on each other. The Grammartranslation world of L2 teaching and learning gave way to the discrete-point world of structuralists, Universalists, and functionalists. The world of competence in FL/SL that started with linguistic competence gradually developed into performance, functional or communicative competences (Bachman, 1990; Bardovi-Harling, 2002; Chomsky, 1965; Hymes, 1972; cited in May, 2009), pragmatic competence (Grice, 1989; Morris, 1994; Rose \& Kasper, 2001), pragmalinguistics and sociopragmatics (Leech, 1983; Thomas, 1983), and now scholars are talking of intercultural communicative competence (Savignon, 2006) and Intercultural pragmatics (Wierzbicka, 2006). Intercultural competence is gaining its due credit in L2 teaching, learning and testing for it is well accepted that language without culture is nonexistent. Furthermore, "Given the dialogic nature of culture (Bakhtin, 1981), we cannot fully understand one culture in the absence of contact with other cultures" (Savignon, 2006, p.102). Therefore, at this juncture of the recognition of the developmental trend of culture in L2 teaching and learning, studies on culture in two culturally different societies of western English world and Eastern world, e.g. Iranian and its role within EFL classes and among EFL students' speech community in Iran, can be contributive both socio-culturally and pedagogically.

L2 learning is accompanied with Second Culture Acquisition (SCA) which can be either facilitating or hampering to L2 learners (Libben \& Lindner, 1996). Probably some of the EFL learners in our society are having difficult times finding ways to overcome the conflicting situations between their L1 culture and L2 culture. This lack of feel-at-home context in some of the EFL learners will have its negative consequences on learners' achievements and calls for proper treatments; otherwise, our EFL programs will yield in either some linguistically competent but interculturally incompetent graduate at its best or some alienated EFL speakers who will time and again suffer from a feeling of guilt of going through a process that is bringing about some kind of erosion on their L1 culture.

Personality and self-identity is a dynamic and developmental phenomenon that in the course of life gradually gets more solidified. Regarding this dynamic nature of identity, Hymes (1974) states "Culture is transmitted, shaped, and maintained through language and dialogue" (Hymes, 1974, cited in Finnan \& Swanson, 2000, p. 67). EF language learners experience this identity development in two linguistic milieus; whereas, Monolinguals' cultural identity is constructed in their L1 environment within which there exists only a monolithic cultural world.

Studies on bilinguals' biculturality reflecting the idea that some bilinguals live and behave in two cultural domains L1 culture and L2culture - have been conducted in the second language domain (Libben \& Lindner, 1996; Mariam \& Kaushankaya, 2005; Yasuko, 2003). The case of learning English in a foreign language domain, which can be specific to every nation, such as Persian, Arabic, Turkish, Japanese, etc. has not been much investigated. The sociocultural aspect and the pedagogical of an enriched identity reconstruction among Iranian EFL students were investigated within Norton's (1995) Investment Model (Bahrami, 2012). The developmental trend of the Multicultural Personality Traits (MPTs) of Iranian EFL students was investigated among BA, MA, and Ph.D. students as well as the correlation between rate MPTs and their English language proficiency and it was found that there is a significant degree of correlation between MPTs development and EFL proficiency. Therefore within this understanding, this study was designed to investigate the effect of Teaching EFL with cultural orientation on EFL students' MPTs development that consequently results in higher EFL proficiency.

\section{Methodology}

This study attempted to investigate the impact of teaching Reading Comprehension with Multicultural Awareness Raising Orientations on the MPTs' development of Iranian students. The objective of the study was formulated in the following research question.

1. Does teaching Reading Comprehension with a Cultural Consciousness-Raising Orientation result in developing a significant level of Multicultural Personal Traits in the participants? 
All possible efforts were made to use the proper and reliable measurement tools to collect the required data that could resolve the issue raised by the research question. The possibility of falling into the pitfall of prejudice and subjectivity in dealing with cultural issues was avoided by providing maximum care and placing a greater weight on its objective scale. Then the research question, was transformed and rewritten in the following null form to help carry out this research in an empirical manner.

1. Teaching Reading Comprehension classes with a Cultural Consciousness-Raising Orientation to nurture MPTs does not result in developing a significant level of MPTs in EFL students.

\section{a. instrument}

Individual's MPTs introduced by Oudenhoven and Van der Zee (2001) and Libben and Lindner's (1996) Stress Reduction Strategies were used in the EG Reading Comprehension classes. The open-end discussion sessions on the five multicultural personal traits -cultural empathy (CE), open-mindedness (OM), social initiative (SI), emotional stability (ES) and flexibility (FL)- were constructed in Reading Comprehension classes in the experimental group to help raise L2 students' awareness of these personality traits that contribute to individuals' multicultural understanding and would consequently facilitate their achievement of intercultural competence and higher English language proficiency. As proposed by Tomlinson and Masuhara (2004), L2 learners were helped to arrive at an "awareness" of the culture rather than accumulating bits of "information" or "knowledge" about the culture.

Multicultural Personality Questionnaire (MPQ) developed by Van der Zee and Oudenhoven at the University of Groningen in the Netherlands (2001) was used in this study to measure the participants' MPTs. It is used to identify individuals' capability of adjustment to other cultures (Van der Zee \& Oudenhoven, 2000; Burkard \& Ponterotto, 2008). MPQ is a 91-item personality assessment questionnaire based on which participants can be rated on a 5-point likert scale, receiving a range of scores from 91-455. It measures five personality features, recognized as Multicultural Personality Traits (MPTs), which are Cultural Empathy (CE), Open-mindedness (OM), Social Initiative (SI), Emotional Stability (ES), and Flexibility (FL).

\section{b. Participants}

The 83 Participants of this experimental study comprised 71 EFL BA students in their second term at Allameh Tabataba'i University and 12 students at the School of International Relations (SIR). Normally these students are randomly assigned to different reading comprehension classes. Five RC(II) classes were randomly selected. Two classes, one at Allameh Tabataba'i with 24 students and one at School of International Relations with 12 students, were treated as the experimental group and three classes were set to be the control group. It was found that one student at the experimental group was an international student from Palestine; therefore, she was excluded from this group and there were 35 students (17 male, 18 female) left in the EG. Five students in CG failed to complete the post-test; therefore, 42students (13 male, 29 female) were left in this group. All of the classes were taught for one semester in the spring of 2012.

\section{c. Data Collection Procedure}

This study was conducted to measure the rate of development in participants' MPTs while attending a Reading Comprehension course with cultural orientation. The control group was treated in normal traditional manner of holding Reading Comprehension classes. The study was carried out among EFL BA students going through their second term at Allameh Tabataba'i University and School of International Relations. There were five Reading Comprehension classes. These five classes were randomly assigned to the experimental groups and the control ones and were taught RC(II) for one term. At the very beginning of the term all groups took MPQ as the pretest. And at the end of the term again they were post tested to find out about the differences in the results potentially resulting from the treatment offered to the experimental groups. Table 1 presents the design of this part of this study.

Both EGs and CG had taken Reading Comprehension (II). The materials used in all classes were reading comprehension texts that are regularly used in RC classes with the aim and objective to improve students' reading comprehension skills by means of helping them with various tactics of efficient reading with comprehension plus increasing their treasury of vocabulary. But in the experimental group, MPTs were meant to be nurtured by means of raising participants' multicultural awareness. The control group was just attending regular Reading Comprehension (II) classes. The experimental groups received the special treatment meant to raise their cultural consciousness in the area of MPTs; whereas, the control groups were treated in the common conventional manner of teaching Reading Comprehension classes. Then both groups were post-tested. The amounts of change in terms of MPTs were measured between both control and the experimental groups to see whether any meaningful differences between the experimental and control groups could be recognized that could be attributed to the given treatment. The collected data of Pre-test and post-test and were analyzed by means of using SPSS 15 to see whether the treatment that the experimental group had been offered resulted in any significant differences or not.

\section{d. Treatment applied in the Experimental Group}

The experimental group and the control group both took Reading Comprehension (II). The experimental groups were treated with a Cultural Awareness-Raising Orientation. The objective of the treatment given to the experimental group was to raise their cultural awareness. In order to materialize cultural awareness in the participants in the experimental groups, the approach taken was to use every effort in the classroom activities and assignments to call students' attention to cultural aspects and help them improve their multicultural personal awareness. The following four basic theoretical 
and practical aspects of teaching RC with a cultural consciousness raising orientation were executed in accordance with the descriptions provided below.

1. The approach taken toward the various aspects of this class

2. Classroom tasks and activities

3. Assignments

4. Evaluation

\section{e. The Approach Taken in the EG}

Every item in language, no matter how small, from the very small prosodic elements, to sophisticated complex syntaxes, contains and conveys some contextual/sociopragmatic meanings and intentions alongside with its semantic meaning. The contextual/sociopragmatic meanings of utterances are their cultural aspects. Therefore, in the treatment groups care and attention was taken and applied to make sure that every task and activity in this class was in line with the approach that every linguistic element has cultural dimensions without which the comprehension and interpretation of them will not be comprehensive. So, within every part and stage of this class, cultural aspects of the text were the guiding key terms for presentation and practice and evaluation.

Awareness of MPTs was initiated in this class by providing proper opportunities in the activities and behaviors of all the participants to help nurture it. MPTs cannot be nurtured in individuals without engaging in interactions with others. Every student in order to develop his MPTs need interlocutors to help bring them into existence by means of establishing social interactions. Students in the experimental group were helped to recognize the importance of the others presence and participation in providing them the possibility of exercising and improving their MPTs. Every one of the five items of MPTs is a multi-pillar construction that is in need of interlocutors to be materialized and practiced. None of the five MPTs can be exercised or materialized by individuals alone. MPTs do not come into existence alone and cannot be sustained in a mono-polar self-interest-seeking world. All these aspects of MPTs were well taken care of in the experimental group classes in classroom discussions and activities.

The complementary nature of culture in language learning, i.e. the diversity and multiculturality in human communities that every L2 learner should be made aware of, was presented to the participants in this approach. It can be said that objective in these classes was to present reading comprehension materials with cultural orientations and the aim was to raise participants' multicultural awareness. The personality traits contributing to multicultural awareness were tried to be fostered in the EG to prepare the ground in these EFL learners for a higher and richer intercultural understanding that is expected to lead to a higher L2 proficiency achievements.

In teaching a foreign language, as linguistic elements are identified, presented, and tried to ascertain that the learners come to understand them and also employ them properly in their speeches and writings, cultural aspects of every item should also be equally treated. L2 learning, from cultural perspective, is exposed to new and sometimes different readings of the world, life and existence that require specific frames to be constructed. Sometimes, L1 cultural frames do not meet the requirements of L2 cultural items and world; therefore, L2 learners should be helped to be creative in making new frames for every new cultural theme they come across in their learning of their new language. In fact learning a new language calls for an innovative attitude and the five MPTs are the basic prerequisites for such innovations to come into existence. In the reading comprehension classes offered in this study every effort conducive to MPTs. EG participants were provided with opportunities to foster the mentioned five MPTs.

In the reading texts, every item's cultural aspects were identified and introduced in a critical and analytical manner by having the students participate in the discussions and contribute to the collectively constructed understandings. It was tried to convey the idea that every L2 learner should search for the cultural features of every item next to their linguistic and semantic features. For example, while presenting the word "pet" it was make clear that this word linguistically and semantically means just an animate noun referring to an animal kept at home by some people. But in the native English speaking communities, it has got its social and legal status to the extent that $a$ pet is counted in as a family member with its own legal rights. A pet is no longer referred as "it"; it is given equal linguistic referent and is referred to as either "he" or "she" and is believed to deserve equal respect like the other member of the family. A pet has got some legal rights as well. If it is a small bird, it cannot be kept alone in a cage or it cannot be left alone at home; otherwise, the owners have to face legal persecutions for their violations of the pets' rights. Governments are responsible to pay for the attorneys to defend the pets' cases in lawsuits. Similar types of cultural features accompany every linguistic element and these aspects of English language were treated appropriately in the experimental RC classes.

It should be made crystal clear that raising cultural consciousness and nurturing multicultural personality traits is not teaching culture of any specific speech community; rather it is nurturing an attitude in language learners to arouse their cultural attentiveness and consciousness towards the reception and recognition of new cultural values. The EG's RC class attempted to broaden the EFL learners' viewpoint in their approach towards learning a new language by means of directing them to create the socio-pragmatic features of the new words rather than finding their best Persian equivalents. If EFL students mean to learn a new language in its perfect holistic and get well aware of its cultural aspects, they essentially need to broaden their approach to equate a bird's view and deepen it to touch a feeling of a philosopher's.

f. Classroom Tasks, Activities and Assignments 
All the classroom activities possessed a discursive nature and were presented in a dialogic and interactional manner and were not just seeking satisfactions at the comprehensive level, but rather going further to help foster a broad band capability in sharing mutual perspectives with the native speakers. Students were encouraged to take adventure in presenting their even diverse viewpoints. Participants were guided to develop their own insight and understanding of the diversity of viewpoints in every human community. A brainstorming type of communal gathering were managed to dominate the classroom with no preference already established, except the fact that diversity is a real piece of human communities.

The manner of treatment in the EG was believed to have a greater effect than transfer of knowledge and data on MPTs. As Planken, Van Hooft, and Korzilius (2004) have found cultural awareness can best be achieved by language learners' "participation" in cultural acts rather than focusing "primarily on internalizing knowledge". Therefore, the generation of the concept of MPTs and its development and promotion were materialized through the trend presented, practiced and established in the classroom activities rather than preaching it. And it was the teacher's responsibility to set a perfect example of MPTs in the deeds conducted in the classroom rather than lecturing the students on the merits of possessing MPTs.

The scope of classroom tasks in this experiment was meaning-based and interactional. It was tilted towards raising participants' awareness of sociopragmatic aspect of the linguistic forms by means of implementing the Noticing Hypothesis. Once the new material was presented and its comprehension was achieved, the teacher would present an objective, scientific and academic understanding of the issue under discussion and prepare the ground for everyone in the class to enjoy his/her right of voicing his/her own reading, interpretation and analysis of the issue. All of the participants were practically witnessing everyone's chance of expressing his/her viewpoints and being respected and challenged by the others and providing the others with equally the same right. This type of classroom activities was expected to help nurture all personality features of MPTs in the EG's students.

Regarding the classroom activities and the available time, the reading materials, as far as their reading comprehension was concerned, were managed to be covered in the $1^{\text {st }}$ third of every session. This preparatory step paved the way for the following discursive activities that were the main tasks distinguishing the EG's classes from the other regular RC classes.

Manner of teaching, including all teaching activities, can be more conducive to cultural achievement than mere transfer of data and knowledge on culture. Intercultural competence can best be achieved by language learners "participation" in cultural acts and observation of cultural behaviors rather than "focus[ing] on internalizing knowledge" (Planken, Van Hooft \& Korzilius, 2004, p. 309). Of course participation in cultural acts in its real sense is almost beyond an EFL context. The best possibility to take care of the shortcomings of a FL environment in nurturing sound and sane cultural awareness that will not be criticized as foreign culture inculcation is discussion-based language teaching and learning classes in which language learners will be offered chances to participate in discussions around the axis of cultural issues. The participatory nature of discussion-oriented language learning classes will help the learners to put into practice their L2 aural/oral skills and raise their awareness of cultural diversity of human communities. The quality of discussions enriched by every student's participation and contributions will help them broaden their scope of mind and come to visualize cultural issues from different perspectives. Discussion-based L2 classes can best serve the recognition, materialization and promotion of MPTs in L2 learners that is sought in most forthcoming multicultural human communities. Discussion-based language classes help development MPTs. Students' participation and contributions of their viewpoints will materialize their meaningful integration into the cultural system and can guarantee the achievement of "cultural awareness-raising" and "production" (Planken, Van Hooft \& Korzilius, 2004, p. 312). Ten passages about CE, SI, OM, ES, and FL were prepared and used in EG to raise their cultural consciousness and improve their MPTs.

Participants in the experimental groups were informed of the theme and subject of every session's text and were given the text a week earlier. They were assigned to go over the text and come to class rich and prepared for discussions. Every student was given a chance to present his/her viewpoints that were used to initiate the ensuing whole-class discussions. The students' participations were given credits as well as the content of their viewpoints. The reading subjects were presented along a continuum somewhere on which every human being might decide to fall and find his interests. The aim pursued was to assist the participants to develop an understanding that the real world is not a black and white dichotomous world and there are many greyly tinted areas between black and white.

\section{RESULTS AND ANALYSIS}

Finally, MPTs of the EGs and CGs were compared by means of applying an Independent-sample t-test for the comparison of the means between experimental and control groups' posttests. Then every one of the subsets of MPTs was also compared in the experimental and control groups to find out the effects of applied treatment in every one of the subcategories of MPTs. Pretest and posttest scores of the experimental groups were also compared by means of applying a paired t-test of means to see if any meaningful difference between the two could be identified. 
TABLE 1:

PARTICIPANTS IN THE EXPERIMENTAL PART OF THE STUDY

\begin{tabular}{|l|l|}
\hline Experimental Groups & Control Groups \\
\hline 35 EFL BA students taking Reading Comprehension (II) & 42 EFL BA students Taking regular \\
+ & Reading Comprehension (II) \\
Teaching centered on nurturing & + \\
Cultural Awareness & No special treatments \\
\hline
\end{tabular}

As mentioned earlier, EGs and CGs were both pre and post tested on their MPTs. The results found for the EG are presented in table 2. As indicated in bold figures, EG students' MPTs raised from 268.03 to 271.14 from $t_{1}$ to $t_{2}$. Then this was analyzed through a t-test comparison of means (Table 3 ) and it was found that:

- There was not a statistically significant increase in MPTs scores from $t_{1}(M=268.03, S D=12.636)$ to $t_{2}[M=271.14$, $\mathrm{SD}=11.565, \mathrm{t}(\overline{34)}=1.588, \mathrm{p} \leq .05]$.

- There was not a statistically significant increase in OP, SI, ES and FL scores of all participants from $t_{1}$ to $t_{2}$.

- But there was a statistically significant value found in the scores of Cultural Empathy $(\mathrm{CE})$ from $\mathrm{t}_{1}(\mathrm{M}=55.20, \mathrm{SD}=$ 2.67) to $\mathrm{t}_{2}[\mathrm{M}=56.49, \mathrm{SD}=2.79, \mathrm{t}(34)=2.35 ; p \leq .05]$.

TABLE 2:

DESCRIPTIVE STATISTICS OF THE EG'S MPTs IN POST AND PRE-TESTS (N=35)

\begin{tabular}{lllll} 
Pairs & MPTs & Mean & SD & Std. Error Mean \\
\hline \multirow{2}{*}{ Pair 1 } & Post Multicultural Personality Traits & $\mathbf{2 7 1 . 1 4}$ & 11.66 & 1.97 \\
\cline { 2 - 5 } & Pre Multicultural Personality Traits & $\mathbf{2 6 8 . 0 3}$ & 12.63 & 2.13 \\
\hline \multirow{2}{*}{ Pair 2} & Post Cultural Empathy & 56.49 & 2.79 & .47 \\
\cline { 2 - 5 } & Pre Cultural Empathy & 55.20 & 2.67 & .45 \\
\hline \multirow{2}{*}{ Pair 3 } & Post Open-Mindedness & 55.23 & 3.17 & .53 \\
\cline { 2 - 5 } & Pre Open-Mindedness & 54.37 & 2.77 & .46 \\
\hline \multirow{2}{*}{ Pair 4 } & Post Social Initiative & 54.91 & 3.78 & .64 \\
\cline { 2 - 5 } & Pre Social Initiative & 54.60 & 4.44 & .75 \\
\hline \multirow{2}{*}{ Pair 5 } & Post Emotional Stability & 52.31 & 4.88 & .826 \\
\cline { 2 - 5 } & Pre Emotional Stability & 52.14 & 4.92 & .83 \\
\hline \multirow{2}{*}{ Pair 6 } & Post Flexibility & 52.20 & 3.28 & .55 \\
\cline { 2 - 5 } & Pre Flexibility & 51.71 & 4.03 & .68
\end{tabular}

TABLE 3:

PAIRED SAMPLES T-TEST STATISTICS MPTS BETWEEN POST AND PRE-TESTS OF THE EXPERIMENTAL GROUP

\begin{tabular}{|c|c|c|c|c|c|c|c|}
\hline \multirow[b]{2}{*}{ Paired Variables } & & \multicolumn{3}{|c|}{ Paired Differences } & \multirow[b]{2}{*}{$\mathrm{t}$} & \multirow[b]{2}{*}{ df } & \multirow[b]{2}{*}{$\begin{array}{l}\text { Sig. } \\
\text { (2-tailed) }\end{array}$} \\
\hline & & Mean & $\mathrm{SD}$ & $\begin{array}{l}\text { Std. Error } \\
\text { Mean }\end{array}$ & & & \\
\hline Pair 1 & Post MPTs \& Pre MPTs & 3.11 & 11.60 & 1.96 & 1.58 & 34 & .12 \\
\hline Pair 2 & Post \& Pre Cultural Empathy & 1.28 & 3.23 & .54 & 2.35 & 34 & $.02 *$ \\
\hline Pair 3 & Post \& Pre Open-Mindedness & .85 & 3.01 & .50 & 1.68 & 34 & .10 \\
\hline Pair 4 & Post \& Pre Social Initiative & .31 & 5.07 & .85 & .36 & 34 & .71 \\
\hline Pair 5 & Post \& Pre Emotional Stability & .17 & 4.17 & .70 & .24 & 34 & .810 \\
\hline Pair 6 & Post \& Pre Flexibility & .48 & 3.51 & .59 & .81 & 34 & .42 \\
\hline
\end{tabular}

The effect size for the above t-test was calculated and the eta-squared value was found to be .069.

Having conducted pre and posttests on MPTs of the CGs, an independent samples t-test comparison of means was conducted between EG's and CG's MPTs. The results found, as presented in Table 6, were as follows:

- There was no significant difference in scores for participants in the experimental group $(\mathrm{M}=271.14, \mathrm{SD}=11.66)$ and the participants in the Control group $[M=268.26, S D=14.16 ; t(75)=.96]$. The magnitude of the difference in the means was small (eta $=.012)$.

- There was $\underline{\text { not }}$ a statistically significant difference in CE, OP, SI, ES, and FL scores of experimental and control groups.

- The effect size for the MPTs in the above t-test was calculated by means of applying eta squared formula and it was found to be .012 .

Therefore the null hypothesis could not be rejected. 
TABLE 4:

DESCRIPTIVE STATISTICS OF CONTROL GROUP's MPTS IN POST AND PRETESTS (N=42)

\begin{tabular}{|c|c|c|c|c|c|c|c|}
\hline \multirow[b]{2}{*}{ Groups } & \multirow[b]{2}{*}{ Variables } & \multirow[b]{2}{*}{ Min. } & \multirow[b]{2}{*}{ Max. } & \multirow[b]{2}{*}{ Mean } & \multirow[b]{2}{*}{ SD } & \multicolumn{2}{|c|}{ Skewness } \\
\hline & & & & & & Statistic & $\begin{array}{l}\text { Std. } \\
\text { Error }\end{array}$ \\
\hline \multirow{4}{*}{$\begin{array}{l}\text { CG } \\
\text { Post-test }\end{array}$} & Post MPTs & 237 & 295 & 268.26 & 14.16 & .03 & .36 \\
\hline & Post Open-Mindedness & 45 & 65 & 54.48 & 5.49 & .04 & .36 \\
\hline & Post Social Initiative & 44 & 65 & 54.71 & 4.39 & .10 & .36 \\
\hline & Post Emotional Stability & 44 & 65 & 52.12 & 4.19 & .44 & .36 \\
\hline \multirow{6}{*}{$\begin{array}{l}\text { CG } \\
\text { Pre-test }\end{array}$} & Pre MPTs & 236 & 294 & 267.95 & 15.08 & -.03 & .36 \\
\hline & Pre Cultural Empathy & 43 & 63 & 55.17 & 4.14 & -.54 & .36 \\
\hline & Pre Open-Mindedness & 43 & 68 & 54.48 & 5.75 & .16 & .36 \\
\hline & Pre Social Initiative & 44 & 66 & 54.76 & 5.04 & .35 & .36 \\
\hline & Pre Emotional Stability & 43 & 66 & 52.07 & 4.92 & .38 & .36 \\
\hline & Pre Flexibility & 44 & 60 & 51.48 & 3.28 & .20 & .36 \\
\hline
\end{tabular}

TABLE 5:

DESCRIPTIVE STATISTICS OF EXPERIMENTAL AND CONTROL GROUPS' MPTS AND ITS SUBCATEGORIES IN POST-TEST

\begin{tabular}{lllll} 
Variables & Groups & N & Mean & SD \\
\hline \multirow{2}{*}{ Post Multicultural Personality Traits } & Experimental G. & 35 & $\mathbf{2 7 1 . 1 4}$ & 11.66 \\
\cline { 2 - 5 } & Control G. & 42 & $\mathbf{2 6 8 . 2 6}$ & 14.16 \\
\hline \multirow{2}{*}{ Post Cultural Empathy } & Experimental G. & 35 & 56.49 & 2.79 \\
\hline \multirow{2}{*}{ Post Open-Mindedness } & Control G. & 42 & 55.33 & 3.29 \\
\hline \multirow{2}{*}{ Post Social Initiative } & Experimental G. & 35 & 55.23 & 3.17 \\
\cline { 2 - 5 } & Control G. & 42 & 54.48 & 5.49 \\
\hline \multirow{2}{*}{ Post Emotional Stability } & Experimental G. & 35 & 54.91 & 3.78 \\
\hline \multirow{2}{*}{ Post Flexibility } & Control G. & 42 & 54.71 & 4.39 \\
\hline & Experimental G. & 35 & 52.31 & 4.88 \\
\cline { 2 - 5 } & Control G. & 42 & 52.12 & 4.19 \\
\cline { 2 - 5 } & Experimental G. & 35 & 52.20 & 3.28 \\
\hline
\end{tabular}

TABLE 6:

INDEPENDENT SAMPLES T-TEST STATISTICS FOR POST-TEST MPTS BETWEEN EXPERIMENTAL AND CONTROL GROUPS' MPTS

\begin{tabular}{|c|c|c|c|c|c|c|c|}
\hline \multirow{2}{*}{ Variables } & \multicolumn{3}{|c|}{$\begin{array}{l}\text { Levene's Test for Equality of } \\
\text { Variances /EV assumed }\end{array}$} & \multicolumn{4}{|c|}{ t-test for Equality of Means } \\
\hline & $\mathrm{F}$ & Sig. & $\mathrm{t}$ & df & $\begin{array}{l}\text { Sig. } \\
\text { (2-tailed) }\end{array}$ & $\begin{array}{l}\text { Mean } \\
\text { Dif. }\end{array}$ & $\begin{array}{l}\text { Std. Error } \\
\text { Dif. }\end{array}$ \\
\hline Post MPTs & 1.53 & .21 & .96 & 75 & .33 & 2.88 & 2.99 \\
\hline Post CE & .822 & .36 & 1.63 & 75 & .10 & 1.15 & .70 \\
\hline Post Op M & 9.928 & .00 & .71 & 75 & .47 & .75 & 1.05 \\
\hline Post Social Initiative & .582 & .44 & .21 & 75 & .83 & .20 & .94 \\
\hline Post Emotional Stability & 2.920 & .09 & .18 & 75 & .85 & .19 & 1.03 \\
\hline Post Flexibility & 1.007 & .31 & .82 & 75 & .41 & .58 & .70 \\
\hline
\end{tabular}

\section{DISCUSSIONS AND CONCLUSION}

The findings on the effect of teaching Reading Comprehension classes with a cultural consciousness raising orientation on developing MPTs indicated that there was not a statistically significant increase in the MPTs scores from $T_{1}$ to $T_{2}$ in the EGs. But it was found that $C E$ of the participants gained significant difference fromT $T_{1}$ to $T_{2}$. Therefore, it can be concluded that the direct teaching of MPTs in EFL classes will not result in developing higher MPTs. The achievements of this study are suggestive of the fact that MPTs' development, having essentially a cultural nature, is a subject residing between the lines and do not yield itself to be subject to teaching for they are themselves subject of teaching. MPTs, like culture that gradually results in identity, are not nouns to gain the right of their possession or ownership, they are verbs to be witnessed and acted out.

Gaining personality traits and personalizing them in identity construction, even in the context of the first language, is a lifelong process; therefore, in the context of L2 learning that brings about the possibility of exposure to a second culture a rather long time is required to test the impact of personality traits acquired in L2 milieu.

\section{a. Theoretical and Pedagogical Implications}

The findings and the concluding discussions of this study indicated that cultural elements are not readily identifiable and cultural development is not easily achievable through direct teaching. Furthermore, the idea of teaching culture to quicken the materialization of investment in the new language through which L2 learning can be facilitated has its pros and cons in the pedagogical spheres. Supporter of this idea might favor its implementation at any cost and opponents might oppose it altogether.

Culture acquisition is a gradual long-term process that has the potential capability to have significant impacts on L2 learners' personal ontological perspectives so it does not yield itself easily to short-term experimental studies. 
Experimental cultural studies require tracing the developments at least on a time span of a generation, long enough to engrave certain specific impressions on the mind of the participants. If the second terms freshmen participants of this study could have been traced after four years of their studying EFL and their outgoing-MPTs be compared with their incoming-MPTs, it could have provided much more generalizable results.

\section{b. Suggestions for Further Research}

- The idea that how bilinguality and multiculturality, which can truly be the dire need of the modern world of the global village, can be integrated with national educational curriculums in a way that it will not have negative influences on national language and culture sounds fascinating. How can bilinguality and biculturality be practiced in a manner to enrich students' understanding of their own national language and culture and resolve the concerns that states might have towards these phenomena?

- This study tried to find out the impact of teaching RC classes with a cultural consciousness raising orientation on developing MPTs in EFL students. This study can be furthered to find out the impact of teaching EFL classes with a cultural consciousness raising orientation on every one of the four language skills.

- The freshmen EFL students, at the beginning of their EFL studies, can be pretested to measure their in-coming MPTs. Then after four years of their studies their outgoing-MPTs can be measured. Finally, their MPTs change can be correlated with their academic achievement records and their EFL proficiency accordingly.

\section{REFERENCES}

[1] Ahn, S.J. (2007). Korean ESL learners' pragmatic competence: Motivation, contact, and length of residence. Unpublished Ph.D. dissertation. Texas, A \& M University.

[2] Bachman, L.F. (1990). Fundamental considerations in language testing. Oxford: Oxford University Press.

[3] Bahrami, H.S., (2012). Sociocultural aspects and pedagogical implications of Iranian EFL students' biculturality and bililinguality within cultural awareness. Ph.D. thesis, Allameh Tabataba'i University

[4] Bakhtin, M. (1981). The dialogic imagination: Four essays by M. M. Bakhtin. Austin, TX: University of Texas Press.

[5] Bardovi-Harlig, K. (2002). Pragmatics and Second Language Acquisition. In R. B. Kaplan (Eds.), The Oxford handbook of applied linguistics. Oxford: Oxford University Press.

[6] Burkard, A., \& Ponterotto, J. (2008). Cultural identity, racial identity, and the multicultural personality. In L.A. Suzuki \& J.G. Ponterotto (Eds.), Handbook of Multicultural Assessment ( ${ }^{\text {rd }}$ ed.), (pp.52-73). USA: Jossey-Bass. A Wile Imprint

[7] Chomsky, N. (1965). Aspects of the theory of syntax. Cambridge, MA: MIT Press.

[8] Elgin, h. S. (2000). The Language imperative: the power of language, enrich your life and expand your mind. London: Perseus Books Group.

[9] Feng, A. (2009). Identity, acting interculturally, and aims for bilingual education: an example from China. Journal of Multilingual \& Multicultural Development, 30 (4), 283- 296.

[10] Finnan, C., \& Swanson, J. D. (2000). Accelerating the learning of all students. Denver: West View Press.

[11] Fogle, E.W., (2007). Language socialization in internationally adoptive family: Identities, second languages, and learning. Ph.D. thesis, Graduate School of Arts and Sciences of Georgetown University

[12] Hamers, J., \& Blanc, M. (2000). Bilinguality and bilingualism.( $\left.2^{\text {nd }} e d.\right)$. Cambridge: Cambridge University Press.

[13] Hinkel, E. (2006). Culture, interaction, and learning. In E. Hinkel, (Ed.), (2006). Culture in second language teaching and learning (6 $6^{\text {th }}$ Ed.).Cambridge: Cambridge University Press.(pp. 1-13).

[14] Kramsch, C. (2005). Language and culture. Oxford: Oxford University Press.

[15] Leech, G. (1983). The principles of pragmatics. London: Longman

[16] Libben, G. \& Linder, O. (1996). Second culture acquisition and second language acquisition. Retrieved from URL:http:// zif.spz.tu-darmstadt.de/jg-ol-1/beitrag/libben2.htm.

[17] Marian, V., \& Kaushanskaya, M. (2005). Autobiographical memory and language in bilinguals. Retrieved from: www.lingerf.com/4/116ISB4.PDF.

[18] May, J. (Ed.) (2009). Concise encyclopedia of pragmatics. UK: Elsevier Ltd.

[19] Morris, P. (1994). (Ed), The Bakhtin reader: Selected writings of Bakhtin, Medvedev and Voloshinov. London: Edvard Arnold, a member of Holdder Headline Group.

[20] Norton, B.P. (1995). Social identity, investment, and language learning. TESOL Quarterly, 29(1), 9-31.

[21] Norton, B. \& Toohey, K. (2002). Identity and language learning. In R.B. Kaplan (Ed.) The Oxford Handbook of applied Linguistics (pp.115-123) New York: Oxford University Press.

[22] Norton, B. Language and Identity. In N. Hornberger and S.L. McKay (Ed.), Sociolinguistics and language education (pp. 349370). Bristol: Short Run Press.

[23] Peterson, E. \& Coltrane, B. (2003). Culture in second language teaching. Retrieved Jan.19 ${ }^{\text {th }}$, 2011, Available at URL: http://www.cal.org/resources/Digest/0309peterson.html.

[24] Rose, K., \& Kasper, G. (2001). Pragmatics in language teaching. Cambridge: Cameras University press.

[25] Savignon, S.J. (2006). Communicative Language Teaching. In J. May, (Eds.) (2009). Concise Encyclopedia of Pragmatics. Oxford: Elsevier Ltd.

[26] Thomas, J. (1983). Cross-cultural pragmatic failure. Applied linguistics, 4.91 - 112.

[27] Tomlinson, B. \& Masuhara, H. (2004). Developing cultural awareness. Modern English Teacher 1(13).5-11.

[28] Van Der Zee, K.I., \& Van Oudenhoven, J.P. (2000). The Multicultural Personality Questionnaire: A multidimensional instrument of multicultural effectiveness. European Journal of Personality, 14, 291-309.

[29] Van der Zee, K.I. \& Brinkmann, U. (2002). Assessments in the intercultural field: The intercultural readiness check and the multicultural personality questionnaire. International Business Investigation Quarterly (IBI), l (2), 1-16. 
[30] Wierzbicka, A. (2006). Intercultural Pragmatics and Communication. In J. May, (Ed.) (2009). Concise Encyclopedia of Pragmatics. UK: Elsevier Ltd.

[31] Yasuko, K. (2003). Negotiating bilingual and bicultural identities: Japanese returnees betwixt two worlds. ( Review) Lawrence Eribaun Association.

Hossein Samadi Bahrami earned his PhD in TEFL at the University of Allameh Tabataba'i, Tehran, Iran in 2012. He is currently teaching as an assistant professor at the School of International Relations (SIR). He is also the head of the Department of the International and Persian languages at SIR and has been teaching phonology, linguistics, ESP of mass media, ESP of political Science at SIR, Islamic Azad University, Ferdosi, and Allameh Tabataba'i Universities for more than 20 years. He has concentrated his research activities on interactional relationships and indissoluble link between language, culture, and identity among bilinguals. He is conducting researches on cultural awareness, personality development and enrichments in the milieu of SLL as well as on internationalization in higher education. 